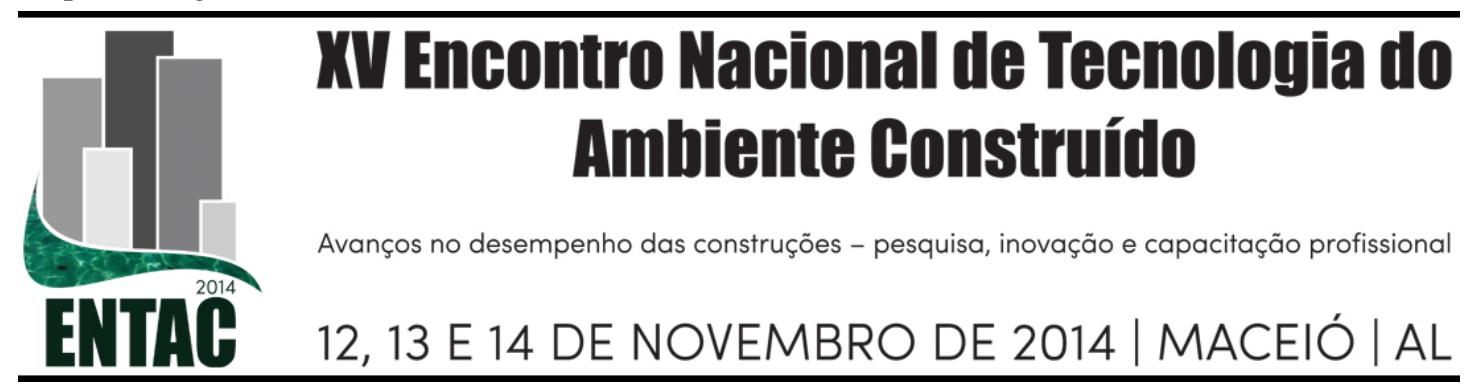

\title{
RESISTÊNCIA À FLEXÃO E ADERÊNCIA DE PASTA DE GESSO OBTIDA POR RECICLAGEM DE RESÍDUOS
}

\author{
SALES, Angela Teresa Costa (1); SANTOS, Débora de Góis (2); RIBEIRO, \\ Karollina Ferreira (3)
}

(1) Universidade Federal de Sergipe, telefone (79) 2105-6700, e-mail: angelasales19@gmail.com (2) Universidade Federal de Sergipe, e-mail: deboragois@yahoo.com.br (3) NM Engenharia e Construções Ltda, e-mail: karollbita@hotmail.com

\begin{abstract}
RESUMO
A geração de resíduos na construção civil tem-se mostrado como grave questão a ser abordada sob o enfoque do seu aproveitamento, convertendo-os em insumos para setores produtivos, inclusive como novos materiais de construção. Diante da significativa geração de resíduos de gesso nas obras, faz-se necessário o desenvolvimento de práticas de reutilização e reciclagem destes resíduos. Esse trabalho é resultado de pesquisa experimental de trabalho de conclusão de curso de Engenharia Civil. Teve como objetivo analisar o desempenho de pastas de gesso, compostas por gesso reciclado e gesso convencional, visando à reciclagem do primeiro, através de ensaios de resistência à flexão e aderência. No procedimento empregado, resíduos de gesso foram reciclados por trituração, calcinação a $200^{\circ} \mathrm{C}$ e peneiramento. Analisou-se a pasta de gesso composta pela mistura do gesso comercial com o gesso reciclado, na proporção de 50\% de cada, comparando seu desempenho ao da pasta de gesso comercial. Para ensaios de flexão em três pontos, foram produzidos corpos de prova prismáticos. Nos ensaios de aderência, utilizaram-se blocos cerâmicos estruturais como substrato, revestidos com pastas de gesso, medindo-se a resistência à tração por arrancamento. Os resultados de ensaios de flexão mostraram redução de apenas $6 \%$ do valor médio do módulo de ruptura, para a pasta com $50 \%$ de substituição, comparando-a a pasta de gesso comercial. Para a aderência, a média dos resultados obtidos para a mistura com $50 \%$ de gesso reciclado e $50 \%$ de gesso comercial superou em $82 \%$ aos obtidos com gesso comercial. As médias dos valores obtidos foram superiores às estabelecidas pela especificação brasileira para revestimentos de tetos e paredes de argamassas inorgânicas em ambientes internos, para os quais se recomenda aplicação de pastas de gesso. Foi possível concluir pela viabilidade da reciclagem do resíduo de gesso e sua aplicação na construção civil.
\end{abstract}

Palavras-chave: Resíduos de gesso, Aderência, Flexão.

\begin{abstract}
The construction waste generation is recognized as a serious issue to be addressed from the standpoint of reutilization by converting them into inputs for productive sectors, including as new building materials. Due the significant generation of gypsum wastes in construction sites, it is necessary to develop practices of waste reuse and recycling. This work resulted of experimental research for Civil Engineering course completion and aimed to analyze the performance of pastes composed of recycled and conventional plaster by testing the flexural strength and adhesion. In experimental procedure, gypsum wastes were submitted to recycling by grinding, calcination at $200^{\circ} \mathrm{C}$ and sieving. Gypsum pastes were produced by mixing the commercial gypsum with recycled in a proportion of $50 \%$ of each and compared their performance with the commercial gypsum slurry. Three points bending tests were made. For bonding tests, structural ceramic blocks were used as substrate, coated with these pastes and bond strength was measured by pullout. The results of bending tests showed a reduction of only $6 \%$ of the average value of the rupture modulus for the paste with $50 \%$ substitution compared to commercial gypsum paste. For bonding tests, the average of results for the mixture containing $50 \%$ recycled gypsum and $50 \%$ commercial gypsum exceeded $82 \%$ those obtained with commercial gypsum. The mean values were
\end{abstract}


higher than those established by the Brazilian specification of mortars for coatings of ceilings and internal walls. It was concluded by the feasibility of recycling waste gypsum and its application in construction.

Keywords: Gypsum wastes, Bond strength, Flexural strength.

\section{INTRODUÇÃ̃O}

A preocupação com a questão da sustentabilidade e necessidade de adoção de tecnologias ecologicamente viáveis está amplamente disseminada, em vários setores da sociedade, visando ao desenvolvimento que não comprometa o suprimento de recursos naturais para as gerações futuras. O crescimento do setor da construção civil é fator preponderante e decisivo para a adoção estratégias que visem à redução, reutilização e reciclagem de resíduos, já que a não geração, neste estágio de conhecimento, ainda não é possível. Na construção civil, resíduos diversos são gerados e o gesso é um dos mais danosos ao meio ambiente. Segundo John e Cincotto (2003), o gesso pode afetar a composição e pH da água e do solo. Nos canteiros, atenção especial deve ser dada a este resíduo, pois sua deposição incorreta pode provocar sérios danos ao solo e aos mananciais.

A Resolução $n^{\circ} 307$ (CONAMA, 2002) estabeleceu que o gesso se enquadrava na classe de resíduos para a qual ainda não havia viabilidade na sua reciclagem e reutilização. Porém a Resolução $n^{0} 431$ (CONAMA, 2011) alterou essa classificação, incluindo os resíduos de gesso na Classe $\mathrm{B}$, que agrupa os "resíduos recicláveis para outras destinações". No entanto, levanta-se a hipótese de que seja viável sua reinserção, após reciclagem, em produtos e serviços da própria construção civil. Este trabalho teve o objetivo de analisar as possibilidades de reciclagem e reutilização deste resíduo, especificamente para produção de pré-moldados e como revestimento de alvenarias.

\section{FUNDAMENTAÇÃO TEÓRICA}

O gesso, que é o composto principalmente por sulfato de cálcio hemidratado $\left(\mathrm{CaSO}_{4} \cdot 0,5 \mathrm{H}_{2} \mathrm{O}\right)$, é um material ecologicamente adequado e extremamente versátil. Em sua produção é lançado na atmosfera apenas vapor de água, ao contrário do que se verifica na produção de cal e cimento, com emissão de $\mathrm{CO}_{2}$. Segundo John e Cincotto (2010), o gesso comum de construção demanda, para sua fabricação, um baixo consumo de energia. Enquanto a temperatura para produção do clínquer Portland é cerca de $1450^{\circ} \mathrm{C}$ e a da cal está entre $800^{\circ} \mathrm{C}$ e $1100^{\circ} \mathrm{C}$, a do gesso não ultrapassa $350^{\circ} \mathrm{C}$.

$\mathrm{Na}$ construção civil, é usado na produção do cimento Portland, como componente retardador da pega do clínquer Portland. Segundo John e Cincotto (2010), a aplicação nacional está voltada para produção de pastas ou argamassas para revestimentos de alvenaria, fabricação de blocos de vedação pré-moldados e painéis para forros e divisórias. A gipsita, que é composta, em sua maior parte, por sultato de cálcio bihidratado (gipso), é um mineral encontrado na natureza de forma abundante e geralmente ocorre associado à anidrita. Sua composição química média apresenta 32,5\% de $\mathrm{CaO}, 46,6 \%$ de $\mathrm{SO}_{3}$ e $20,9 \%$ de $\mathrm{H}_{2} \mathrm{O}$. Ao ser desidratada parcialmente, origina o semi-hidratado, ou sulfato de cálcio hemidratado, que é o gesso (MUNHOZ; RENÓFIO, 2006).

A fabricação do gesso se constitui de três etapas. O minério gipsita é a matéria-prima que, no Brasil, é encontrada de forma abundante. Para a produção do gesso, deve ser extraída, deve passar pelo processo de moagem ou britagem e, posteriormente, é feita a queima ou calcinação. No Brasil, as principais reservas de gipsita ocorrem no 
Amazonas, Pará, Maranhão, Tocantins, Rio Grande do Norte, Piauí, Ceará, Pernambuco e na Bahia. Existem, ainda, registros de ocorrências do minério nos estados de Sergipe, Rio de Janeiro, Acre e Rondônia (LYRA SOBRINHO et al., 2001). No processo de queima da gipsita $\left(\mathrm{CaSO}_{4} \cdot 2 \mathrm{H}_{2} \mathrm{O}\right)$, são perdidas $1 \frac{1}{2}$ molécula de água, transformando 0 material em sulfato de cálcio hemidratado, conforme a Equação 1, que já é o próprio gesso. Após a moagem para obtenção do grau de finura adequado, está pronto o aglomerante.

$$
\mathrm{CaSO}_{4} \cdot 2 \mathrm{H}_{2} \mathrm{O} \rightarrow 140^{\circ} \mathrm{Ca} 160^{\circ} \mathrm{C} \rightarrow \mathrm{CaSO}_{4} \cdot 0,5 \mathrm{H}_{2} \mathrm{O}+1,5 \mathrm{H}_{2} \mathrm{O}
$$

Após a aplicação, na forma de pasta ou, menos frequentemente, em argamassas, dá-se a reação de hidratação, recompondo o sulfato bi-hidratado original, conforme a Equação 2.

$$
\mathrm{CaSO}_{4} \cdot 0,5 \mathrm{H}_{2} \mathrm{O}+1,5 \mathrm{H}_{2} \mathrm{O} \rightarrow \mathrm{CaSO}_{4} \cdot 2 \mathrm{H}_{2} \mathrm{O}
$$

O processo de calcinação pode variar quanto à temperatura em que é executado e quanto ao tipo de forno utilizado. Segundo Canut (2006), gesso estuque, gesso para reboco e gesso de alta resistência podem ser obtidos, a depender da temperatura e das condições de realização da calcinação. Entre a temperatura de 140 a $160^{\circ} \mathrm{C}$, já se obtém o hemidrato, ou gesso. A anidrita III, conhecida também como anidrita ativa, é obtida entre as temperaturas de $160^{\circ} \mathrm{C}$ a $250^{\circ} \mathrm{C}$. É um produto pouco solúvel e instável que, absorvendo umidade atmosférica, passa à forma de hemidrato (BALTAR et al., 2005). Segundo Canut (2006), para temperaturas de 250 a $800^{\circ} \mathrm{C}$, a anidrita III transforma-se em anidrita II, produto cuja velocidade de hidratação é lenta. A anidrita I é produzida em temperaturas acima de $800^{\circ} \mathrm{C}$, sendo considerado como gesso de alta resistência.

Segundo Silva et al. (1998), a facilidade para ser moldada que a pasta de gesso, quando fresca, apresenta e seu rápido endurecimento são vantagens da utilização deste material como revestimento, além da leveza do material. John e Cincotto (2010) assinalam que o rápido endurecimento do gesso viabiliza a produção de placas de gesso acartonado, que domina os mercados norte-americano e europeu de divisórias internas de baixo custo. Porém a rapidez do endurecimento da pasta de gesso pode contribuir para a geração de resíduos desse material, quando não há domínio da técnica de aplicação para compatibilizar a quantidade de pasta produzida com a quantidade de revestimento que pode ser aplicado, antes de seu endurecimento.

O que define um bom desempenho mecânico da pasta de gesso é a relação água/gesso da mistura. Comparado ao cimento Portland, o gesso comum não apresenta alta resistência mecânica e sua sensibilidade à umidade é fator limitante para que sua utilização seja ampliada. É caracterizado, ainda, como um material com baixa resistência à abrasão (CANUT, 2006). O gesso possui condutibilidade térmica em torno de $0,3 \mathrm{kcal} / \mathrm{m}^{2} \cdot \mathrm{h}^{\circ} \mathrm{C}$, sendo um bom isolante térmico. Além do conforto térmico e acústico, o gesso, através da absorção de umidade, confere aos ambientes, resistência ao fogo (MARTINS; PAIVA, 2010; CANUT, 2006). O gesso pode ser aplicado como proteção ao fogo em estruturas metálicas (JOHN; CINCOTTO, 2010).

Segundo Yazigi (2002), o tempo de pega e o endurecimento da pasta de gesso sofrem influência da água de amassamento, pois, quanto mais água for empregada na mistura, maior será o tempo de pega. A resistência da pasta se reduz com a utilização de água em excesso, embora um maior teor de água possa contribuir para melhor trabalhabilidade da pasta (MARTINS; PAIVA, 2010).

A utilização do gesso como revestimento de paredes e tetos se dá, principalmente, pela boa ligação deste material com diferentes superfícies. Essa aderência depende de 
características da pasta ou argamassa, como a trabalhabilidade, características da base, como a porosidade e a absorção de água, além da resistência mecânica e textura superficial (CANUT, 2006). Quanto à natureza das superfícies, as pastas de gesso aderem bem a tijolos, pedras e ligas de ferro, mas aderem mal às superfícies de madeira. Em superfícies de ligas de ferro, o gesso não impede a corrosão, tornando necessária a utilização de revestimentos anticorrosivos (MARTINS; PAIVA, 2010). Para determinar esta propriedade, é realizado ensaio de aderência, ou "pull off test", regido por norma brasileira (NBR 13528, 2010). Verificam-se as máximas tensões suportadas pelo revestimento aplicado em um substrato e submetido a um esforço normal de tração (RIBEIRO, 2006).

A vasta utilização do gesso como revestimento e elementos de vedação, além de proporcionar, para a construção civil, maior agilidade no processo construtivo, agregando grande produtividade, gera enorme quantidade de resíduos. Há estimativa, de 2006 , de que $5 \%$ do gesso acartonado e cerca de $35 \%$ do gesso utilizado como revestimento é transformado em resíduo durante a construção (SINDUSGESSO, 2006 apud MUNHOZ e RENÓFIO, 2006). A destinação desses resíduos consiste em grande problema ambiental, econômico e social, visto que esse material muitas vezes é depositado em aterros sanitários de forma incorreta, o que impossibilita seu reaproveitamento. Nos aterros, quando em contato com umidade e condições anaeróbicas e sob a ação de bactérias, pode ser produzido o ácido sulfídrico, que apresenta odor de ovo podre, é tóxico e inflamável (SÁ; PIMENTEL, 2009).

Segundo Munhoz e Renófio (2006), a reciclagem do gesso pode ser viabilizada, cumprindo-se as seguintes etapas: gestão de resíduos, coleta dos resíduos, separação dos contaminantes, processamento, controle da qualidade e comercialização. A gestão consiste na separação do resíduo no próprio canteiro, a pré-seleção deste e a proteção contra umidade. Sem dúvida, a etapa crucial para o reaproveitamento dos resíduos de gesso é a segregação, que nem sempre é feita do modo mais correto. A coleta deve ser feita por transportadores especializados, do canteiro até a empresa de reciclagem. Em seguida, faz-se a separação dos contaminantes, fase que ainda requer muitos estudos, pois pode provocar danos à saúde dos trabalhadores que executarem essa separação, a depender do método escolhido para separar. O produto reciclado deve voltar ao consumidor com garantia de qualidade e compatível com o produto fabricado a partir da matéria prima original, a gipsita.

Para John e Cincotto (2003), transformar um resíduo em produto comercialmente viável é tarefa bastante complexa, que necessita de conhecimentos técnicos, legais e de mercado. Além da necessidade desses conhecimentos, para possível reciclagem do gesso, a contaminação, a que este está sujeito, e a existência de poucas áreas para sua deposição dificultam e tornam caro o seu reaproveitamento. Segundo esses autores, a empresa canadense New West Gypsum Recycling encontrou viabilidade no processo de reciclagem e, desde 1986, recicla placas de gesso acartonado e retorna as matérias primas para esta indústria e para as indústrias de fibra de papel. É possível utilizar até $22 \%$ do gesso reciclado sem prejuízo no desempenho dos novos elementos. É imprescindível para a realização deste processo que todos os contaminantes sejam removidos.

Em estudo feito por Niglio e Camarini (2005), analisaram-se as propriedades físicas e mecânicas das pastas de gesso comum e gesso reciclado, produzido a partir de material colhido em campo, com diferentes relações água/gesso. Mesmo diante das impurezas que apresentava o gesso reciclado, foram atingidos valores aceitáveis para os resultados de ensaios, como tempo de início e fim de pega e de determinação das propriedades 
mecânicas. Concluiu-se neste trabalho que o gesso reciclado oferece total compatibilidade com o gesso comum, o que viabiliza o processo de reciclagem.

A aderência é propriedade de fundamental importância para todo e qualquer tipo de revestimento, visto que, para que a durabilidade seja garantida, essa relação entre base e revestimento deve ser mantida. Em pastas de gesso, verifica-se a boa aderência em vários tipos de superfícies, porém, ${ }_{2}$ sua aplicação é melhor e mais facilmente executada em superfícies rugosas e absorventes (NBR 13867, 1997). No caso específico de revestimentos com pasta de gesso, John e Cincotto (2010) consideram que há vantagem de sua aplicação, pois dispensam a aplicação de massa corrida, necessária quando a tinta é aplicada sobre base com argamassa. Devido ao rápido endurecimento, a confecção das pastas de gesso para revestimento é governada pela necessidade de uma reologia adequada à aplicação e pelo tempo útil, em que essa reologia é mantida. O profissional gesseiro deve, com base em sua experiência, definir a relação água/gesso mais adequada, que geralmente varia entre 0,6 e 0,9 . O gesseiro tem que controlar a resistência mecânica da camada de revestimento, que é a aderência máxima do revestimento à base e que costuma ser elevada.

Estudos feitos no Brasil mostraram que a resistência de aderência do revestimento de gesso variou entre 0,4 e 1,7 $\mathrm{MPa}$, que supera aos $0,3 \mathrm{MPa}$ exigidos para revestimentos externos. De modo geral, revestimentos de gesso apresentaram maior aderência em superfícies mais porosas, a exemplo de blocos de concreto, secas e para relações água/gesso mais baixas (JOHN; CINCOTTO, 2010).

\section{METODOLOGIA}

O gesso reciclado foi produzido a partir de pedaços de blocos de gesso para vedação triturados em britador de mandíbulas do Laboratório de Materiais de Construção da UFS e, em seguida, foram mantidos por oito horas em estufa, a $200^{\circ} \mathrm{C}$ e peneirados em peneira com abertura de malha de $2 \mathrm{~mm}$. O gesso comercial foi adquirido no mercado local. A caracterização desses materiais foi realizada no âmbito do trabalho de Sales e Silva (2011) e nos seguintes parâmetros:

- Índice de finura: para o gesso comercial esse valor foi de 0,83 e para o gesso reciclado, 0,46. De acordo com a norma (NBR 13207, 1994), o gesso fino para revestimento deve ter módulo de finura inferior a 1,10 e ambos os materiais estudados atenderam ao exigido.

- Tempos de início e fim de pega: apresentados na Tabela 1. O gesso reciclado apresentou tempos, de início e fim de pega, inferiores aos exigidos pela citada norma. Já o gesso comercial atendeu ao requisito para o tempo de início, mas o tempo de fim de pega ficou um pouco abaixo do exigido.

Tabela 1 - Parâmetros obtidos dos ensaios de tempos de inicio e fim de pega

\begin{tabular}{|c|c|c|}
\hline Tipo de gesso & Tempo de inicio de pega & Tempo de fim de pega \\
\hline Reciclado & $8 \mathrm{~min}$. e $5 \mathrm{seg}$. & $36 \mathrm{~min}$. e $40 \mathrm{seg}$. \\
\hline Comercial & $11 \mathrm{~min}$. e $15 \mathrm{seg}$. & $44 \mathrm{~min}$. e $30 \mathrm{seg}$. \\
\hline $\begin{array}{c}\text { Exigências da NBR } \\
13207 \text { (min.) }\end{array}$ & $>10 \mathrm{~min}$. & $>45 \mathrm{~min}$. \\
\hline
\end{tabular}

Fonte: Sales e Silva, 2010. 
- Resistência à compressão da pasta de gesso (Tabela 2). Segundo a norma (NBR 13207, 1994), esse valor deve ser superior a 8,4 MPa, para a pasta de gesso com relação água/gesso correspondente à consistência normal. Observou-se que, com a substituição de $50 \%$ do gesso comercial pelo gesso reciclado, houve redução de $27,11 \%$ da resistência à compressão, em relação à pasta com 100\% de gesso comercial. Para a pasta com $100 \%$ de gesso reciclado, essa redução foi de 33,97\%. Mesmo a pasta com $100 \%$ de gesso comercial não alcançou o limite de resistência preconizado na citada norma.

Tabela 2 - Parâmetros obtidos dos ensaios de resistência à compressão

\begin{tabular}{|c|c|c|}
\hline \multirow{2}{*}{$\begin{array}{c}\text { Teor de substituição do gesso } \\
\text { comercial por reciclado }(\boldsymbol{\%})\end{array}$} & \multicolumn{2}{|c|}{ Resistência à compressão } \\
\cline { 2 - 3 } & Média (MPa) & Coef. de variação (\%) \\
\hline 100 & 3,14 & 5,4 \\
\hline 50 & 3,46 & 4,4 \\
\hline 0 & 4,75 & 6,6 \\
\hline
\end{tabular}

Fonte: Sales e Silva, 2010.

No âmbito desse estudo, realizaram-se ensaios mecânicos de flexão das pastas e de aderência do revestimento com essas pastas. Para ambos os ensaios, foi produzida uma pasta com $50 \%$ de gesso comercial e $50 \%$ de gesso reciclado, além da pasta com $100 \%$ de gesso comercial, tomada como referência. Utilizou-se relação água/gesso de 0,6. Para ensaios de aderência, foram produzidos corpos de prova com aplicação de camada de revestimento sobre blocos cerâmicos estruturais. Registra-se a tentativa de produzir corpos de prova de pasta com $100 \%$ de gesso reciclado, porém houve sérias dificuldades em produzir a mistura. A pega muito rápida não permitiu o manuseio da mistura que possibilitasse a produção de elementos com as mínimas condições de homogeneidade e adensamento. Essa grande reatividade pode estar relacionada com o processo de produção do gesso reciclado, tais como a temperatura e o tempo de calcinação.

Os corpos de prova para ensaio de flexão, prismáticos, mediam $50 \mathrm{~cm}$ x $50 \mathrm{~cm}$ x 300 $\mathrm{cm}$. O molde foi preenchido com a pasta em camada única, submetida a adensamento em mesa vibratória por 15 segundos. Foram moldados, para cada pasta, seis corpos de prova. A desmoldagem se deu com 24 horas e fez-se a cura por mais seis dias, em saco plástico vedado. Aos sete dias de idade, os corpos de prova foram rompidos (Figura 1ab).

Figura 1 - Corpo de prova antes da ruptura (a). Corpo de prova após ruptura (b)
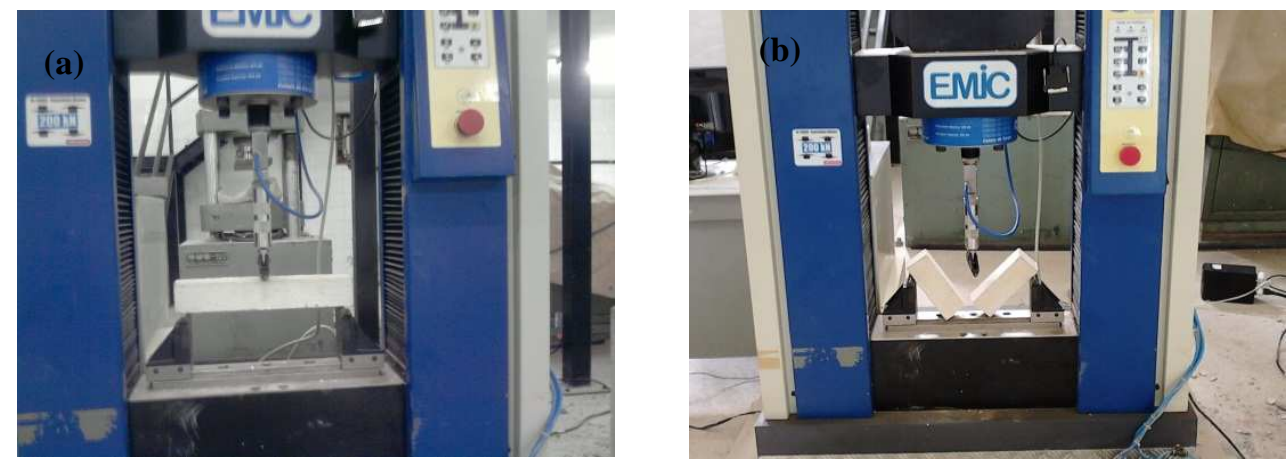
Para cada tipo de pasta, foram revestidos dois blocos cerâmicos, em uma das faces, com uma camada de pasta com espessura que variou de 5 e $10 \mathrm{~mm}$. Cada bloco comportava duas regiões para fixação do aparelho de arranchamento. Os ensaios foram realizados após 7 dias de aplicado o revestimento.

\section{RESULTADOS E DISCUSSÃO}

\subsection{Ensaios de flexão}

Os resultados obtidos dos ensaios de flexão em três pontos, com as pastas de gesso estudadas, encontram-se na Tabela 3.

Tabela 3 - Parâmetros obtidos nos ensaios de flexão

\begin{tabular}{|c|c|c|}
\hline \multirow{2}{*}{ Pasta de gesso } & \multicolumn{2}{|c|}{ Parâmetros dos ensaios de flexão } \\
\cline { 2 - 3 } & $\begin{array}{c}\text { Módulo de ruptura médio } \\
(\mathbf{M P a})\end{array}$ & $\begin{array}{c}\text { Coef. de } \\
\text { variação (\%) }\end{array}$ \\
\hline $50 \%$ de gesso reciclado + 50\% de gesso comercial & 1,88 & 7,51 \\
\hline $100 \%$ de gesso comercial & 2,00 & 3,19 \\
\hline
\end{tabular}

Percebeu-se que, com a substituição de $50 \%$ do gesso comercial pelo gesso reciclado, houve uma redução de apenas $6 \%$ do valor médio do módulo de ruptura (MOR) no ensaio de flexão. Considerando o potencial de reaproveitamento do resíduo convertido em aglomerante, notou-se que, mesmo incorporando um significativo percentual de gesso reciclado, o prejuízo ao desempenho mecânico, sob esse tipo de solicitação, foi pouco relevante. Foi possível notar maior velocidade das reações, pela substituição do gesso comercial pelo reciclado.

\subsection{Ensaios de aderência de revestimento de gesso}

Os resultados obtidos dos ensaios de arrancamento de revestimento, realizados com as pastas de gesso estudadas, encontram-se na Tabela 4.

Tabela 4 - Resultados dos ensaios de aderência de revestimento

\begin{tabular}{|c|c|c|}
\hline Pasta de gesso & $\begin{array}{c}\text { Resistência média à tração no } \\
\text { arrancamento (MPa) }\end{array}$ & $\begin{array}{c}\text { Coef. de variação } \\
(\%)\end{array}$ \\
\hline $\begin{array}{c}50 \% \text { de gesso reciclado }+50 \% \text { de } \\
\text { gesso comercial }\end{array}$ & 0,65 & 5,7 \\
\hline $100 \%$ de gesso comercial & 0,36 & 24,3 \\
\hline
\end{tabular}

Os resultados dos ensaios mostraram que houve $82 \%$ de aumento da resistência à tração no arrancamento do revestimento (aderência), quando houve a substituição de $50 \%$ de gesso comercial pelo gesso reciclado. Ambas as pastas atenderam plenamente às exigências da norma (ABNT, 1996), pela qual o valor mínimo de resistência de aderência do revestimento é de 0,2 $\mathrm{MPa}$, para ambiente interno, e 0,3 $\mathrm{MPa}$, para ambiente externo. Considerando que o revestimento de gesso deve ser usado apenas em áreas internas, pode-se concluir que a pasta que contém o gesso reciclado apresentou resistência correspondente a 3,23 vezes o valor mínimo exigido. Os resultados obtidos 
para aderência estão comparáveis com valores citados por John e Cincotto (2010), correspondente aos resultados de estudos no Brasil, que estavam entre 0,4 e 1,7 MPa.

Quanto ao modo de ruptura na ligação revestimento-substrato, percebeu-se que a ruptura se deu, em quase todos os ensaios de arrancamento, na interface entre os dois materiais, sem que houvesse ruptura da pasta de gesso ou ruptura do substrato. Notou-se que a camada de revestimento era retirada quase por inteiro (Figura 2a-b). Apenas em um dos ensaios, foi percebido que houve ruptura do substrato, notando-se parte da superfície do bloco cerâmico aderida ao revestimento. Mas, mesmo assim, não foi na maior parte da área de arrancamento e esse valor foi desprezado.

Figura 2 - Aspecto das áreas de arrancamento do revestimento de gesso
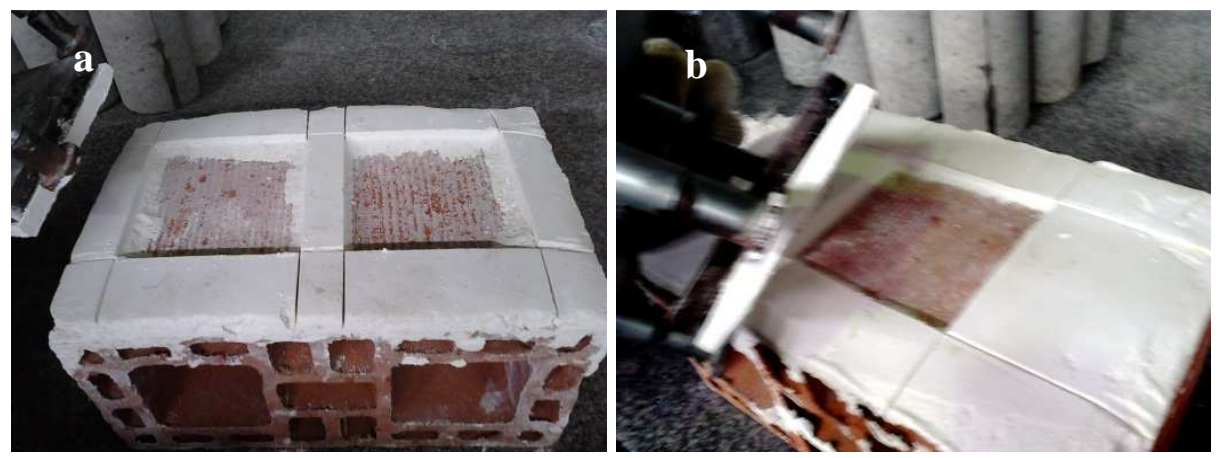

\section{CONCLUSÕES}

Dos resultados obtidos dos ensaios de flexão em três pontos, foi possível concluir que, com a substituição de $50 \%$ do gesso comercial pelo gesso reciclado, houve uma pequena redução $(6 \%)$ em relação à pasta com $100 \%$ de gesso comercial. Esse resultado habilita a utilização de considerável percentual de gesso reciclado na produção de elementos que possam sofrer este tipo de solicitação. Pode-se supor que essa resistência a flexão, tão próxima da resistência do gesso comercial, esteja relacionada à alta reatividade percebida.

Quanto aos ensaios de resistência à tração no arranchamento, concluiu-se que houve $82 \%$ de aumento da aderência do revestimento, com a substituição parcial do gesso comercial por gesso reciclado, em relação à pasta composta somente gesso comercial. Tanto o revestimento com pasta de gesso comercial, quanto o que continha gesso reciclado, atenderam às exigências da norma. No modo de ruptura na ligação revestimento-substrato prevaleceu a ruptura entre revestimento e substrato, mostrando que os valores obtidos representaram a resistência de aderência do revestimento.

Concluiu-se que a aplicação do gesso reciclado produzido na forma adotada, substituindo parcialmente o gesso comercial, é viável do ponto de vista do desempenho mecânica à flexão e aderência de revestimento.

\section{REFERÊNCIAS}

ASSOCIAÇÃO BRASILEIRA DE NORMAS TÉCNICAS. NBR 13207: Gesso para construção civil. Especificação. Rio de Janeiro, 1994.

NBR 13528: Revestimento de paredes e tetos de argamassas inorgânicas Determinação da resistência de aderência à tração. Método de Ensaio. Rio de Janeiro, 2010. 
NBR 13867: Revestimento interno de paredes e tetos com pasta de gesso - Materiais, preparo, aplicação e acabamento. Procedimento. Rio de Janeiro, 1997.

NBR 13749: Revestimento de paredes e tetos de argamassas inorgânicas Especificação. Rio de Janeiro, 1996.

BALTAR, C.A.M., BASTOS, F.F., LUZ, A.B. Gipsita. In: Rochas e minerais industriais. Rio de Janeiro: CETEM, 2005.

CANUT, M.M.C. Estudo da viabilidade do uso do resíduo fosfogesso como material de construção. 2006. Dissertação (Mestrado em Construção Civil), Universidade Federal de Minas Gerais, Belo Horizonte.

CONAMA - Conselho Nacional de Meio Ambiente. Resolução no 307, de 05 de julho de 2002. Brasília: MMA/CONAMA, 2002.

CONAMA - Conselho Nacional de Meio Ambiente. Resolução n $\mathbf{n}^{0}$ 431, de 25 de maio de 2011. Brasília: MMA/CONAMA, 2011.

JOHN, V.M., CINCOTTO, M.A. Alternativas de gestão dos resíduos de gesso. http://www.reciclagem.pcc.usp.br/ftp/Alternativas $\% 20$ para $\% 20$ gestão $\% 20 \mathrm{de} \% 20$ resiudos $\% 20 \mathrm{~d}$ e\%20gesso\%20v2.pdf, 2003.

JOHN, V.M., CINCOTTO, M.A. Gesso na construção civil. In: Geraldo C. Isaia (org.). Materiais de construção civil e princípios de ciência e engenharia de materiais. 2 ed., v. 1. São Paulo: IBRACON, 2010, p. 727-759.

LYRA SOBRINHO, A.C.P., AMARAL, A.J.R., DANTAS, J.O.C., DANTAS, J.R.A. Gipsita. In: Balanço Mineral Brasileiro 2001. DNPM, 2001.

MARTINS, J.G., PAIVA, P.A. Materiais de Construção I - Ligantes, $3^{\text {a }}$ ed. Universidade Fernando Pessoa, Lisboa, Portugal, 2010.

MUNHOZ, F.C., RENÓFIO, A. Uso da Gipsita na Construção Civil e adequação para a P+L. In: XIII SIMPEP. Bauru, São Paulo, 2006.

NIGLIO, F., CAMARINI, G. Viabilização Técnica e Econômica da Reciclagem dos Resíduos de Gesso. In: XIII CONGRESSO INTERNO DE INICIAÇÃO CIENTÍFICA DA FACULDADE DE ENGENHARIA CIVIL, ARQUITETURA E URBANISMO - FEC, UNICAMP. Anais... Campinas, São Paulo, 28 e 29 de setembro de 2005.

RIBEIRO, A.S. Produção de gesso reciclado a partir de resíduos oriundos da construção civil. 2006. Dissertação (Mestrado em Engenharia Civil), Universidade Federal da Paraíba, João Pessoa.

SÁ, N.H.R., PIMENTEL, L.L. Avaliação do Desperdício de Gesso Aplicado como Revestimento. In: XIV ENCONTRO DE INICIAÇÃO CIENTÍFICA - PUC. Anais... Campinas, 2009.

SALES, A.T.C., SILVA, D.T. Reciclagem de gesso a partir de resíduos de blocos de gesso In:

$2^{\circ}$ ENCONTRO NACIONAL SOBRE APROVEITAMENTO DE RESÍDUOS NA

CONSTRUÇÃO E II SEMINÁRIO SOBRE RESÍDUOS SÓLIDOS NA CONSTRUÇÃO

CIVIL, 2011, Maceió. Anais... Maceió: ENARC, 2011. v.único.

SILVA, A.P., STARLING, C.M.D., ARAÚJO, P.H.M. Estudo do Desempenho Físico e Mecânico em gesso Aditivado para Acabamentos na Construção Civil. In: VII ENCONTRO NACIONAL DE TECNOLOGIA DO AMBIENTE CONSTRUÍDO. Anais... Florianópolis, 1998.

YAZIGI, W. A técnica de edificar. 4a ed. São Paulo: PINI, 2002. 